\title{
Nutrient fluctuation has different effects on a tropical invader in communities from the native and non-native range
}

\author{
Yulong Zheng ${ }^{1}$, Jean Burns ${ }^{2}$, Zhi-Yong Liao ${ }^{3}$, and Weitao $\mathrm{Li}^{4}$ \\ ${ }^{1}$ Xishuangbanna Tropical Botanical Garden, Chinese Academy of Sciences \\ ${ }^{2}$ Case Western Reserve University \\ ${ }^{3}$ Affiliation not available \\ ${ }^{4}$ Xishuangbanna Tropical Botanical Garden
}

April 28, 2020

\begin{abstract}
Fluctuating resource hypothesis proposed that resource fluctuation facilitates the successful invasion of exotic plant. Biotic resistance hypothesis proposed that more species rich communities should be more resistant to invasion. Here, we synthesize these ideas in a single experiment with the invader, Chromolaena odorata in 315 artificial communities with resident plants from native and non-native ranges. We found that the effects of nutrient fluctuation on invasion success are contingent on resident origin (native vs. non-native range), and this effect was weaker in more species rich communities. Our results suggest a novel twist on the fluctuating resource hypothesis: suggesting that it is more powerful in species poor communities of nonnative origin. This also suggests that competition for fluctuating resources may be one mechanism governing biotic resistance hypothesis (e.g. the effects of richness were greater when resources were fluctuating).
\end{abstract}

\section{Key words}

Invasion, exotic plant, nutrient fluctuation, resident origin, richness.

\section{INTRODUCTION}

The fluctuating resource hypothesis is a popular theory that explains exotic plant invasion (Davis et al . 2000). This hypothesis suggests that resource fluctuation usually increases resource availability, which will provide invasion opportunities for non-native species, and the resident communities will be more susceptible to invasion (Davis et al . 2000; Li \& Stevens, 2012). Davis et al . (2000) proposed that invasion of exotic species usually increased when resources were supplied as large-magnitude pulses rather than at continuous rates; however, evidence for the resource fluctuation hypothesis is mixed. We propose that effects of fluctuating resources on invader success (e.g. invader biomass) might depend upon the region of origin (e.g. native vs. non-native range) of resident plants and the species richness of the resident community.

Some studies across multiple ecosystems provide supporting evidence that resource fluctuation is associated with invasion of non-native species (Leishman \& Thomson 2005; Hobbs \& Atkins 2006; Radford 2013). In Germany, the invasion of several invaders was increased by rainfall fluctuation (Kreyling et al . 2008), consistent with this hypothesis. However, Walker et al . (2005) found fluctuation of water or nutrient resources did not increase the rate of invasion of the herbaceous perennial Hieracium pilosella (Asteraceae). The invasion of the annual grass Schismus arabicus (Poaceae) was also greater under continuous resource supply compared to fluctuating resource supply (James et al . 2006).

These apparent inconsistencies might be due in part to differences in how resident species respond to resource fluctuations. Different resident plants have different physiological requirements and ecological strategies (Li 
\& Stevens 2012). In our previous work, we demonstrated that plants from the native range of invasive plant Chromolaena odorata (Mexico) had faster relative growth rates than those from the non-native range (China) (Zheng et al . 2018; Burns et al . 2019). If greater relative growth rates correspond to a greater ability to utilize fluctuating resources (James \& Richards 2005; Keser et al . 2014), then species from C. odorata 's native range should be better at suppressing invader performance than those from the non-native range, especially when resource availability is fluctuating. Thus, we predict that the effects of fluctuating resource availability might be contingent on resident community structure, including the origin (native or introduced ranges) of the resident community.

Whether fluctuating resource availability effects on invasion are contingent on resident plant richness is also unclear. Species richness of resident communities plays an important role in resistance to invasion of nonnative plants, as suggested by the biotic resistance hypothesis (Elton 1958). Some studies found community richness was negatively related with the invasion of exotic plants (Maron \& Marler 2008; Zheng et al . 2018), consistent with this hypothesis. A few studies have proposed that resource fluctuation and richness have interactive effects on invasion of exotic plants (Davis \& Pelsor 2001; Petchey et al . 2002; Thomsen et al . 2006). High-richness communities usually have diverse ecological niches and complementary resource use patterns (in time, space) (Naeem et al . 2000), perhaps suggesting that high richness communities should be robust to resource fluctuations (less invasible, regardless of fluctuation level) (Smeti et al . 2018; Tredennick et al . 2017). Therefore, we predict the effect of resource fluctuation on invasion should be greater in low-richness communities than in high-richness communities.

We use the invader Chromolaena odorata to experimentally test whether the fluctuating resource hypothesis is contingent on resident plant origin and species richness. Chromolaena odorata is an invasive plant in some tropical and subtropical areas; Chromolaena odorata can invade diverse habitats especially in disturbed environments (Raimundo et al . 2007; Zheng et al . 2018). If disturbance induces resource (light, water, or nutrient) fluctuations (Symstad 2000; Gross et al . 2005; Radford 2013; Seipel et al . 2018), the successful invasion of $C$. odorata might be due to differences between native and non-native resident plants response to resource fluctuation. In this study, in order to test how invasion is influenced by resource fluctuation, species range (native vs. non-native range), richness and their interactive effects, we created a series of artificial communities with resident plants from native (Mexico) and non-native (China) ranges. We replicated within and across 3 levels of species richness (1,2 and 4 resident species communities) for a total of 315 experimental mesocosms. We hypothesized that (1) the invasion success will be suppressed in communities from the native range (Mexico), especially with fluctuating resource availability, if fast growing residents take advantage of fluctuating resource availability and suppress the growth of the invader, (2) the invasion success will be facilitated with fluctuating resources in communities from the non-native range (China), because these resident species are slower growing and less able to take advantage of resource pulses compared with the invader, and (3) high richness communities will be less influenced by resource fluctuation than low richness communities, if resource complementarity makes high richness communities more robust to perturbation.

\section{Materials and Methods}

\section{Study site}

A common garden experiment was conducted at Xishuangbanna Tropical Botanical Garden of Chinese Academy of Sciences (XTBG-CAS) (21 $56^{\prime}$ N, 101deg15'E) located in Mengla County, Yunnan Province, southwest China. In this area, the mean annual temperature is 21.7 . In July, the hottest month, the mean temperature is 25.3 , and in January, the coolest month, the mean temperature is 15.6 . The average annual precipitation of this site is $1557 \mathrm{~mm}$, with a dry period lasting from November to April (Zheng et al . 2015, 2018).

\section{Study materials}

Chromolaena odorata (L.) R. M. King and H. Robinson (Asteraceae) is a semi-lignified perennial subshrub, which is native to Latin America. In the middle of the $19^{\text {th }}$ Century, $C$. odorata was introduced to some tropical areas as ornamental plants (Zheng et al . 2018). Over hundreds of years, it became one of the most 
seriously noxious invasive species in the world, and caused great threats to biodiversity and environments (Qin et al . 2013; Zheng et al . 2015, 2018).

In this study, in order to test whether the effect of resource fluctuation on invasion success of $C$. odorata was different between native and non-native origin communities, in March 2017, we established a series of artificial communities in the common garden using resident plants from Mexico (native range) and China (non-native range) (Table S1). Each community included 16 individuals of Mexican or Chinese resident species and nine individuals of $C$.odorata. Three types of artificial communities were used: one resident species, two resident species (eight individuals per species) and four resident species (four individuals per species; Fig. S1). The seeds of resident species from Mexico (Morelos and Veracruz) and China (Xishuangbanna and Pu'er) were collected in 2011, 2012, 2014. The seeds of Chromolaena odorata were collected from Xishuangbanna in 2012. These species were selected because they were common and have sympatric distributions with $C$. odorata at each collection site. Seeds of each species were collected from more than 10 individuals, spaced at least $20 \mathrm{~m}$ apart and mixed uniformly in paper bags. These seeds were germinated, and seedlings were planted in a common garden at XTBG-CAS. To reduce maternal effects, we used the seeds of each species from this common garden for our experiments. According to our previous study, the performance of the Mexican species growing in China was similar as their performance in the field in Mexico (Zheng et al ., 2018).

\section{Construction of artificial communities}

Due to the limitation of seed amount for some species, we chose 18 species combinations $(8,7$ and 3 combinations with one, two and four resident species respectively) for artificial communities with resident species from China, and 17 combinations ( 7,7 and 3 combinations with one, two and four resident species respectively) for artificial communities with resident species from Mexico (Table S1). The rule of species combination was that the species in each combination have sympatric distributions in the field. The size of each experimental community was $2 \mathrm{~m} \times 2 \mathrm{~m}$, and each community was $1 \mathrm{~m}$ apart from neighbouring communities. Each species combination had nine community replicates, for a total number of 315 experimental communities. Communities of each combination were randomly arranged in the common garden.

In March 2017, the seeds of each species were geminated in a greenhouse in XTBG-CAS, and in June 2017, similar sized seedlings were transplanted into the artificial communities. The seedlings of resident and invasive plants were planted to the communities at the same time. During the first 15 days, the seedlings were watered daily at a rate of $30 \mathrm{~L}$ per artificial community. Then seedlings were grown under natural conditions. Weeds were removed carefully when necessary.

\section{Nutrient treatments}

During July to November, artificial communities received nutrient treatments with Germany Lion Horse Compound Fertilizer (nitrogen: phosphorus: potassium 21:8:11). For each species, three artificial communities received a continuous nutrient (Each time, $0.2 \mathrm{~g}$ fertilizer per individual. One time per month, for a total of 5 times), another three artificial communities received a fluctuated nutrient treatment (In September, $1 \mathrm{~g}$ fertilizer per individual). Thus, the two nutrient treatments (continuous and fluctuating) received the same total amount of fertilizer. The last three artificial communities did not receive any nutrient as control.

\section{Biomass harvesting and calculation of invasion success}

In December 2017, we harvested the aboveground parts of all plants, and oven-dried them at 100 degC for $72 \mathrm{~h}$. Then the weight of each individual was measured.

We used the proportion of $C$. odorata biomass to represent invasion success, which was calculated as the equation: the biomass of $C$. odorata / biomass of all plants in the artificial community. A high proportion of $C$. odorata biomass indicated that the invasion success was great, which meant the community was easily invaded by $C$. odorata.

\section{Statistical analysis}


The effects of range (resident species origin), nutrient treatment and richness on invasion success were tested by a linear mixed-effects model. Range, nutrient treatment and richness were treated as fixed factors, and artificial community (species combination) nested within range was treated as a random factor. Data was $\log$ transformed to improve normality of residuals. Analysis was carried out using the lme function in the nlme package (version 3.1-128) in $\mathrm{R}$ version 3.3.2 ( $\mathrm{R}$ Core Team 2016). LSMEANS (version 2.27-61) post hoc tests were used for multiple comparisons of invasion success across different levels of each factor.

Linear (communities with one and four non-native species) or nonlinear regression was used to analyze the relationship of invasion success of $C$. odorata with resident plant biomass.

\section{Results}

Range, nutrient treatment and richness had significant effects on invasion success (Table 1). The interactions of Range $\mathrm{x}$ Treatment and Range $\mathrm{x}$ Treatment $\mathrm{x}$ Richness had significant effects on invasion success, whereas Range $\mathrm{x}$ Richness and Treatment $\mathrm{x}$ Richness had no significant effects on invasion success (Table 1). The invasion success was higher for communities with resident species from non-native range (China) than those from native range (Mexico) (Fig. S1).

For communities with one resident species from non-native range, those that received continuous nutrients had significantly higher invasion success than control, but lower invasion success than those that received fluctuated nutrients (Fig. 1a). For communities with one resident species from native range, those that received continuous and fluctuated nutrients had significantly lower invasion success than control (Fig. 1a). A similar pattern was found in communities with two resident species, however control and continuous treatments did not differ for communities from the non-native range, and continuous and fluctuation treatments did not differ for communities from the native range (Fig. 1b). For communities with four resident species from China or Mexico, there were no significant differences among communities in the continuous nutrient, fluctuated nutrient and control treatments (Fig. 1c).

For communities with resident species from China and Mexico, invasion success was significantly and negatively related with biomass of resident plants (Fig. 2). However, at the same biomass of resident plants, invasion success of $C$. odorata was higher for communities with non-native species than communities with native species (Fig. 2).

\section{Discussion}

Consistent with our hypothesis, nutrient fluctuation had different effects on invasion success of $C$. odorata in communities with species from native and non-native ranges (Table. 1, Fig. 1). For communities with one and two species, resource fluctuation increased invasion success in non-native origin communities (China) but added nutrients decreased invasion success in native origin communities (Mexico) (Fig. 1a, b). Because these resident plants from native range had faster relative growth rates (Zheng et al . 2018; Burnset al . 2019), we expect that they used the added nutrients efficiently and suppressed invader growth. This expectation is also consistent with the negative correlation we observed between invasion success and resident biomass (Fig. 2). The relatively slower growing residents from the non-native range (Zheng et al . 2018; Burnset al . 2019) may be low efficiently take advantage of these resource additions, leading to greater invasion success in non-native communities, especially when resources were fluctuating. Further, resource fluctuation had no effect on invasion in more species richness communities (Fig. 1c). We speculate that diversity diminishes the effect of resource fluctuation, because high-richness communities usually have diverse ecological niches and complementary resource use patterns (Naeemet al . 2000; Ptacnik et al . 2008), such that fluctuated resources will be used more thoroughly in high than in low richness communities.

Invaders have long been thought to be exceptionally good at resource acquisition, having high growth rates and opportunism in the face of high nutrient availability (Qin et al . 2013) or nutrient pulses due to disturbance (Davis et al . 2000; Burns \& Winn 2006). A large number of functional trait studies are consistent with this prediction, finding especially that invaders often have high relative growth rates (e.g. (Burns 2006; Grotkopp \& Rejmanek 2007; Dawsonet al . 2011). Thus invaders often have a more opportunistic resource use 
strategy than their competitors in the non-native range (e.g. Burns \& Winn 2006). Our results demonstrate that most resident species in $C$. odorata 's native range have a faster resource acquisition strategy than the invader, but most residents in non-native range have slower resource use efficiency than the invader. It could explain why tests of the fluctuating resource hypothesis generate inconsistent results. As we demonstrate, invader success in response to nutrient fluctuation was contingent on the resident community's origin (native vs. non-native range), and thus its' resource acquisition strategy (see also Zheng et al . 2018; Burns et al . 2019), suggesting that the fluctuating resource hypothesis will apply only to resident communities with lower resource acquisition strategies, relative to the invader.

We found that higher richness resident communities are less invasible overall, and the invasion success was not influenced by fluctuating resources in these communities, which is generally consistent with the biotic resistance hypothesis (Elton 1958; Beaury et al . 2019) and with studies demonstrating that higher richness communities are more resilient (Naeem et al . 2000; Allan et al . 2011). In particular, experimental studies often found that more species rich resident communities are more resistant to invasions (e.g. Levine 2000), and recent large scale studies found similar patterns (Beaury et al . 2019). It had been suggested that resource complementarity might govern the greater resiliency of more diverse communities (Allanet al . 2011). Though we did not test for complementary resource use here, the negative correlation between invasion success and resident biomass is consistent with resource competition as a possible mechanism influencing the interaction between resident richness and fluctuating resources. Interestingly, this suggests that competition for fluctuating resources may be one mechanism governing the biotic resistance hypothesis, at least in this study system.

The invasion of exotic plants is also related with global change. In the last 200 years, rapid development of industry has triggered unprecedented global environmental changes (Lei et al . 2012, USGCRP 2018). Eutrophication and the addition of nitrogen deposition are two important components of environmental change (Sinha 2017; Zhanget al . 2016; Walker et al . 2019), which induce great nutrient fluctuation in the ecosystem, and might contribute to the successful invasion of exotic species. Meanwhile, with rapid economic development, human beings have modified the landscape, such as deforestation, grassland degradation, desertification, which caused great loss of biodiversity (Walther et al . 2002). On the other hand, besides biodiversity loss, great disturbances of major projects (construction of motorway, railway and reservoir, etc) usually cause the fluctuation of some resources (Radford 2013). According to our results (Fig. 1), in non-native range, biodiversity loss and resource fluctuation may further facilitate the invasion of exotic plants (MacDougall et al . 2009; Maron et al . 2014), though studies replicated across multiple native and non-native ranges would be useful to test the generality of this idea.

In conclusion, nutrient fluctuation had different effects on invasion success of $C$.odorata in communities from the native and non-native ranges for low richness communities. Functional differences between species from the native (Mexico) and non-native (China) ranges, such as differences in relative growth rate might contribute to this pattern. Thus, we found that the fluctuating resource hypothesis explains some variation in the success of the invader, $C$. odorata, and that this effect was contingent on resident plant origin (native vs. introduced range) and species richness of the resident community. We add to the mostly separate literatures on the biotic resistance hypothesis and the fluctuating resource hypothesis, finding that these mechanisms can interact to influence invader performance. Lower diversity communities were generally more vulnerable to invasion, especially when resources were fluctuating, as might be expected with disturbance (Symstad 2000; Gross et al . 2005; Radford 2013; Seipel et al . 2018). In future, biodiversity loss and increasing disturbance could interact to exacerbate the invasion of exotic plants.

\section{Acknowledgements}

This study was funded by the projects of National Natural Science Foundation of China $(31870524,3167020269)$, and the CAS 135 program (No. 2017XTBG-F01). We thank Wenbian Bo and Andu Yang for transplanting and managing these seedlings.

\section{AUTHORSHIP}


YLZ designed the research. YLZ performed the research. YLZ, JHB and ZYL analyzed the data. YLZ, JHB, ZYL and WTL wrote and revised the paper.

\section{DATA ACCESSIBILITY}

If this manuscript is acceptable, we will upload the data to Figshare or Dryad repository.

\section{References}

Allan, E., Weisser. W., Weigelt, A., Roscher, C., Fischer, M. \& Hillebrand H. (2011). More diverse plant communities have higher functioning over time due to turnover in complementary dominant species.Proc . Natl . Acad . Sci . U.S.A ., 108, 17034-17039.

Beaury, E. M., Finn, J. T., Corbin, J. D., Barr, V. \& Bradley, B. A. (2020). Biotic resistance to invasion is ubiquitous across ecosystems of the United States. Ecol . Lett ., 23, 476-482.

Burns, J. H. \& Winn A. A. (2006). Are invasive species more plastic? A comparison of plastic responses to competition by invasive and noninvasive congeners in the Commelinaceae. Biol.Invasions , 8, 797-807.

Burns, J. H. (2006). Relatedness and environment affect traits associated with invasive and noninvasive introduced commelinaceae.Ecol . Appl ., 16, 1367-1376.

Burns, J. H., Jennifer, E. M. \& Zheng, Y. L. (2019). Tests of alternative evolutionary models are needed to enhance our understanding of biological invasions. New Phytol ., 222, 701-707.

Davis, M. A. \& Pelsor, M. (2001). Experimental support for a resource-based mechanistic model of invasibility. Ecol .Lett ., 4, 421-428.

Davis, M. A., Grime, J. P. \& Thompson, K. (2000). Fluctuating resources in plant communities: a general theory of invasibility. $J$.Ecol ., 88, 528-534.

Dawson, W., Fischer, M. \& van Kleunen, M. (2011). The maximum relative growth rate of common UK plant species is positively associated with their global invasiveness. Global Ecol . Biogeogra ., 20, 299-306.

Elton, C. S. (1958). The ecology of invasions by animals and plants. Chapman \& Hall, New York, NY.

Gross, K. L., Mittelbach, G. G. \& Reynolds, H. L. (2005). Grassland invasibility and diversity: responses to nutrients, seed input, and disturbance. Ecology , 86, 476-486.

Grotkopp, E. \& Rejmanek, M. (2007). High seedling relative growth rate and specific leaf area are traits of invasive species: Phylogenetically independent contrasts of woody angiospernis. Am . J .Bot ., 94, 526-532.

Hobbs, R. J. \& Atkins, L. (2006). Effect of disturbance and nutrient addition on native and introduced annuals in plant communities in the Western Australian wheatbelt.Austral Ecol ., 13, 171-179.

James, J. J. \& Richards, J. H. (2005). Plant N capture from pulses: effects of pulse size, growth rate, and other soil resources. Oecologia , 145, 113-122.

James, J. J., Caird, M. A., Drenovsky, R. E. \& Sheley, R. L. (2006). Influence of resource pulses and perennial neighbors on the establishment of an invasive annual grass in the Mojave Desert.J .Arid Environ ., $67,528-534$.

Keser, L. H., Dawson, W., Song, Y. B., Yu, F. H. \& Fischer, M. (2014). Invasive clonal plant species have a greater root-foraging plasticity than non-invasive ones. Oecologia , 174, 1055-1064.

Kreyling, J., Beierkuhnlein, C., Ellis, L. \& Jentsch, A. (2008). Invasibility of grassland and heath communities exposed to extreme weather events additive effects of diversity resistance and fluctuating physical environment. Oikos , 117, 1542-1554. 
Lei, Y. B., Wang, W. B., Feng, Y. L., Zheng, Y. L. \& Gong, H. D. (2012). Synergistic interactions of $\mathrm{CO}_{2}$ enrichment and nitrogen deposition promote growth andecophysiological advantages of invading Eupatorium adenophorum in Southwest China.Planta , 236, 1205-1213.

Leishman, M. R. \& Thomson, V. P. (2005). Experimental evidence for the effects of additional water, nutrients and physical disturbance on invasive plants in low fertility Hawkesbury Sandstone soils, Sydney, Australia. J . Ecol ., 93, 38-49.

Levine, J. M. (2000). Species diversity and biological invasions: relating local process to community pattern. Science, 288, 852-854.

Li, W. \& Stevens, M. H. H. (2012). Fluctuating resource availability increases invasibility in microbial microcosms. Oikos , 121, 435-441.

MacDougall, A. S., Gilbert, B. \& Levine, J. M. (2009). Plant invasions and the niche. J . Ecol ., 97, 609-615.

Maron, J. L. \& Marler, M. (2008). Effects of native species diversity and resource additions on invader impact. Am . Nat ., 172, S18-S33.

Maron, J. L., Auge, H., Pearson, D. E., Korell, L., Hensen, I., Suding, K. N. et al . (2014). Staged invasions across disparate grasslands: effects of seed provenance, consumers and disturbance on productivity and species richness. Ecol . Lett ., 17, 499-507.

Naeem, S., Knops, J. M. H., Tilman, D., Howe, K. M., Kennedy, T. \& Gale, S. (2000). Plant diversity increases resistance to invasion in the absence of covarying extrinsic factors. Oikos , 91, 97-108.

Petchey, O. L., Casey, T., Jiang, L., McPhearson, P. T. \& Price, J. (2002). Species Richness, Environmental Fluctuations, and Temporal Change in Total Community Biomass. Oikos , 99, 231-240.

Ptacnik, R., Solimini, A. G., Andersen, T., Tamminen, T., Brettum, P., Lepisto, L. et al . (2008). Diversity predicts stability and resource use efficiency in natural phytoplankton communities.Proc .Natl . Acad . Sci . U.S.A., 105, 5134-5138.

Qin, R.M., Zheng, Y.L., Valiente-Banuet, A., Callaway, R.M., Barclay, G.F., Silva-Pereyra, C. et al. (2013). The evolution of increased competitive ability, innate competitive advantage, and novel biochemical weapons act in concert to promote invasion for a tropical invader. New Phytol., 197, 979-988.

Radford, I. J. (2013). Fluctuating resources, disturbance and plant strategies: diverse mechanisms underlying plant invasions. J .Arid Land, 5, 284-297.

Raimundo, R. L. G., Fonseca, R. L., Schachetti-Pereira, R., Peterson, A. T. \& Lewinsohn, T. M. (2007). Native and exotic distributions of Siamweed (Chromolaena odorata) modeled using the genetic algorithm for rule-set production. Weed Sci ., 55, 41-48.

Seipel, T., Rew, L. J., Davis, K. T., Maxwell, B. D. \& Lehnhoff, E. A. (2018). Disturbance type influences plant community resilience and resistance to Bromus tectorum invasion in the sagebrush steppe.Appl . Veg . Sci . 21, 385-394.

Sinha, E., Michalak, A. M. \& Balaji, V. (2017). Eutrophication will increase during the 21st century as a result of precipitation changes.Science , 357, 405-408.

Smeti, E., Roelke, D. L., Tsirtsis, G. \& Spatharis, S. (2018). Species extinctions strengthen the relationship between biodiversity and resource use efficiency.Ecol . Model ., 384, 75-86.

Symstad, A. J. (2000). A test of the effects of functional group richness and composition on grassland invasibility. Ecology , 81, 99-109.

Thomsen, M. A., D’Antonio, C. M., Suttle, K. B. \& Sousa, W. P. (2006). Ecological resistance, seed density and their interactions determine patterns of invasion in a California coastal grassland. Ecol .Lett ., 9, $160-170$. 
Tredennick, A. T., Adler, P. B. \& Adler, F. R. (2017). The relationship between species richness and ecosystem variability is shaped by the mechanism of coexistence. Ecol . Lett ., 20, 958-968.

USGCRP. (2018). Impacts, Risks, and Adaptation in the United States: Fourth National Climate Assessment, Volume II [Reidmiller, D.R., C.W. Avery, D.R. Easterling, K.E. Kunkel, K.L.M. Lewis, T.K. Maycock, and B.C. Stewart (eds.)]. U.S. Global Change Research Program, Washington, DC, USA, 1515 pp. doi: $10.7930 / \mathrm{NCA} 4.2018$.

Walker, J., Bell, M. D., Schwede, D., Cole, A., Beachley, G., Lear, G.et al . (2019). Aspects of uncertainty in total reactive nitrogen deposition estimates for North American critical load applications. Sci.Total Environ ., 690, 1005-1018.

Walker, S., Wilson, J. B. \& Lee, W. G. (2005). Does fluctuating resource availability increase invasibility? Evidence from field experiments in New Zealand short tussock grassland.Biol . Invasions , 7 , 195-211.

Walther, G. R., Post, E., Convey, P., Menzel, A., Parmesan, C., Beebee, T. J. C. et al . (2002). Ecological responses to recent climate change. Nature, 416, 389-395.

Zhang, Y. H., Loreau, M., Lu, X. T., He, N. P., Zhang, G. M. \& Han. X. G. (2016). Nitrogen enrichment weakens ecosystem stability through decreased species asynchrony and population stability in a temperate grassland. Glob. Change Biol . 22, 1445-1455.

Zheng, Y. L., Burns, J. H., Liao, Z. Y., Li, Y. P., Yang, J. \& Chen, Y. J. et al . (2018). Species composition, functional and phylogenetic distances correlate with success of invasiveChromolaena odorata in an experimental test. Ecol .Lett ., 21, 1211-1220.

Zheng, Y. L., Feng, Y. L., Zhang, L. K., Callaway, R. M., Valiente-Banuet, A., Luo, D. Q. et al. (2015). Integrating novel chemical weapons and evolutionarily increased competitive ability in success of a tropical invader. New Phytol ., 205, 1350-1359.

\section{Table and figures}

Table 1 Effects of range, nutrient treatment, richness and their interactions on invasion success according to a linear mixed model. Range, Treatment and Richness as fixed factors, and community nested within range as a random factor. Data was log transformed.

\section{Source Sum Square d.f. $F$-value $P$-value}

Range $0.0979111 .6224<\mathbf{0 . 0 1}$

Treatment $0.073124 .3380<\mathbf{0 . 0 5}$

Richness $0.101326 .0111<\mathbf{0 . 0 1}$

RangexTreatment $0.3048218 .086<\mathbf{0 . 0 0 1}$

RangexRichness 0.046422 .75560 .0802

TreatmentxRichness 0.022940 .67820 .6076

RangexTreatmentxRichness $0.160644 .763<\mathbf{0 . 0 0 1}$

Fig. 1

\section{Hosted file}

image1. emf available at https: //authorea.com/users/306872/articles/437908-nutrient-fluctuationhas-different-effects-on-a-tropical-invader-in-communities-from-the-native-and-non-nativerange

Invasion success of $C$. odorata in communities with species from non-native rang and native range at different nutrient treatments. In each small figure, two thicker bars in the center depict the mean+-SE for artificial 
communities with species from China and Mexico respectively, and narrow bars (left for non-native range, right for native range) indicate the mean+-SE for each species combination. Different letters indicate there are significant differences among treatments.

\section{Hosted file}

image3.emf available at https://authorea.com/users/306872/articles/437908-nutrient-fluctuationhas-different-effects-on-a-tropical-invader-in-communities-from-the-native-and-non-nativerange

Fig. 2

The relationship between invasion success of $C$. odorataand biomass of resident plants. 